\title{
Gender Parity in Medical School Does Not Equal Gender Parity in Medical School Leadership
}

\author{
Tariq U. Azam, MD and Amy S. Oxentenko, MD
}

$\mathbf{I}^{\mathrm{s}}$ $\mathrm{N}$ THIS ISSUE of the Journal of Women's Health, Larson et al. ${ }^{1}$ conducted an in-depth study of the gender and rank distribution of dean positions at allopathic medical schools in the United States. Building on prior work that established discrepancies in representation of women in dean positions and documented significantly shorter tenures for women deans, ${ }^{2}$ the authors have demonstrated that women continue to be underrepresented among medical school decanal roles compared with men. In addition, this study found that the proportion of physician deans to nonphysician deans is different for men compared with women, which makes this study novel. Women physicians are less likely to hold decanal positions compared with men physicians, including lower-tier dean positions, a level at which women appear to be given more opportunity. ${ }^{1}$ The goal should be equity of women at all decanal levels and, in addition, equitable representation of women physicians among the group of women deans in a similar proportion to men physicians.

This study builds on an ever-growing body of evidence that demonstrates women physicians are less likely to be recognized or hold leadership positions compared with their men colleagues, as well as nonphysician women. Prior work has demonstrated that women physicians are less likely to be recognized by professional societies with awards and lectureships, ${ }^{3}$ subspecialty presidential leadership positions, ${ }_{5}^{4}$ and as authors of perspective pieces in high-impact journals. ${ }^{5}$ These are only a few representative studies of a much larger robust body of work that spans all specialties, leadership roles, and markers of recognition.

The findings of this current study are in the context of recently achieved gender parity in students matriculating into U.S. allopathic schools in the 2018-2019 academic year. ${ }^{6}$ It is, therefore, tempting to suggest that the underrepresentation of women physicians in both academic and society leadership positions is a time-limited or "pipeline" problem. This view, although seemingly sound on the surface, is inherently flawed. In an excellent review, Dr. Julie Silver, along with a series of guest discussants, gave compelling evidence that the discrepancies seen are not simply due to numbers, but rather, rooted in a complex set of implicit biases, cemented in centuries of societal norms. ${ }^{7}$ The evidence, legal ramifications, and personal experiences around these biases, focusing on "micro-inequities" or unintentional harmful messaging, are staggering.
There are a myriad of challenges with these microinequities. First, the perpetrators of these messages may not recognize their behavior as harmful, which further disseminates biases if one does not acknowledge they exist and attempt to account for them. These sentiments may arise from implicit or unconscious biases. Second, issues related to micro-inequities rarely meet legal criteria for discrimination, leading to perpetuation given there may be a sense that there are no consequences or ramifications. Finally, there are many who may not see such behaviors as harmful, even though they continue to contribute to an unfavorable work environment. In such cases, micro-inequities may lead to macro-inequities.

So what can be done? Carr et al. ${ }^{8}$ evaluated how academic medical institutions are addressing these challenges and found nearly $40 \%$ of the survey participants' institutions had no special programming that was directed at the recruitment, promotion, or retention of women. Most interventions, when present, exist at the individual level, focusing on mentoring or interpersonal skills, whereas fewer institution-wide and policy-wide interventions were reported. To effect change, targeted efforts on a broader academic level are required.

To address the findings of the current study by Larson et al. ${ }^{1}$ as well as the many other studies that preceded it, academic institutions and societies must implement multilevel intentional interventions to shed light on the implicit biases leading to these issues. Recruitment and selection committees at all levels should undergo mandatory implicit bias training, similar to those used to address racial disparities in medical school admissions. ${ }^{9}$ Faculty and leadership development should be structured to demonstrate the evidence behind the known disparities and their causes. Finally, and most critically, leadership at the institution and society levels must create a top-down climate of openness to discuss issues of equity, diversity, and inclusion.

Then, and only then, will the field of medicine see meaningful sustained results.

\section{References}

1. Larson A, Kan C, Silver J. Representation of women physician deans in U.S. Medical Schools. J Womens Health 2019;28:600-605.

2. White FS, McDade S, Yamagata H, Morahan PS. Genderrelated differences in the pathway to and characteristics of U.S. medical school deanships. Acad Med 2012;87:10151023. 
3. Silver JK, Slocum CS, Bank AM, et al. Where are the women? The underrepresentation of women physicians among recognition award recipients from medical specialty societies. PM R 2017;9:804-815.

4. Silver JK, Ghalib R, Poorman JA, et al. Analysis of gender equity in leadership of physician-focused medical specialty societies, 2008-2017. JAMA Intern Med 2019;179:433-435.

5. Larson AR, Poorman JA, Silver JK. Representation of women among physician authors of perspective-type articles in High-Impact Dermatology Journals. JAMA Dermatol 2019; 155:386-388.

6. AAMC. U.S. Medical School Applications and Matriculants by School, State of Legal Residence, and Sex, 2018-2019. AAMC FACTS. 2018. Available at: www.aamc.org/data/ facts Accessed February 21, 2019.

7. Silver JK, Rowe M, Sinha MS, et al. Micro-inequities in Medicine. PM R 2018;10:1106-1114.
8. Carr PL, Gunn C, Raj A, Kaplan S, Freund KM. Recruitment, promotion, and retention of women in academic medicine: How institutions are addressing gender disparities. Womens Health Issues 2017;27:374-381.

9. Capers Q 4th, Clinchot D, McDougle L, Greenwalks AG. Implicit racial bias in medical school admissions. Acad Med 2017;92:365-369.

Address correspondence to: Amy S. Oxentenko, MD, FACP, FACG, AGAF Department of Medicine Mayo Clinic 200 First Street SW Rochester, MN 55905

E-mail: Oxentenko.amy@mayo.edu 